OPEN ACCESS

Edited by:

Olivier Feron,

Université catholique de Louvain,

Belgium

Reviewed by:

Abraham Kuten,

Rambam Health Care Campus, Israe

Shikha Kumari,

University of Nebraska Medical Center,

United States

*Correspondence:

Anke-Hilse Maitland-van der Zee a.h.maitland@amsterdamumc.n

Specialty section:

This article was submitted to Pharmacology of Anti-Cancer Drugs, a section of the journal Frontiers in Pharmacology

Received: 13 January 2020 Accepted: 15 June 2020

Published: 26 June 2020

Citation:

Zazuli Z, Kos $R$, Veltman JD, Uyterlinde $W$, Longo C, Baas $P$, Masereeuw R, Vijverberg SJH and Maitland-van der Zee A-H (2020) Comparison of Myelotoxicity and Nephrotoxicity Between Daily LowDose Cisplatin With Concurrent Radiation and Cyclic High-Dose Cisplatin in Non-Small Cell Lung Cancer Patients.

Front. Pharmacol. 11:975. doi: 10.3389/fphar.2020.00975

\section{Comparison of Myelotoxicity and Nephrotoxicity Between Daily Low- Dose Cisplatin With Concurrent Radiation and Cyclic High-Dose Cisplatin in Non-Small Cell Lung Cancer Patients}

\author{
Zulfan Zazuli ${ }^{1,2}$, Renate Kos ${ }^{1}$, Joris D. Veltman ${ }^{1}$, Wilma Uyterlinde ${ }^{3}$, Cristina Longo ${ }^{1}$, \\ Paul Baas ${ }^{3}$, Rosalinde Masereeuw ${ }^{4}$, Susanne J. H. Vijverberg ${ }^{1}$ \\ and Anke-Hilse Maitland-van der Zee ${ }^{1 *}$ \\ ${ }^{1}$ Department of Respiratory Medicine, Amsterdam UMC, University of Amsterdam, Amsterdam, Netherlands, ${ }^{2}$ Department \\ of Pharmacology-Clinical Pharmacy, School of Pharmacy, Bandung Institute of Technology, Bandung, Indonesia, \\ ${ }^{3}$ Department of Thoracic Oncology, The Netherlands Cancer Institute/Antoni van Leeuwenhoek Hospital, Amsterdam, \\ Netherlands, ${ }^{4}$ Division of Pharmacology, Utrecht Institute for Pharmaceutical Sciences, Utrecht, Netherlands
}

Aim: Antineoplastic effect of cisplatin, the first line treatment in non-small cell lung cancer (NSCLC), is hindered by its nephrotoxicity and myelotoxicity. Both low-dose and highdose regimens are used in the management of NSCLC. The aim of this study is to assess the risk on myelotoxicity and nephrotoxicity from the daily low-dose cisplatin (DLD) treatment as compared to cyclic high-dose cisplatin (CHD).

Methods: A retrospective cohort study was conducted. NSCLC patients treated with cisplatin between 2011 and 2018 in the Amsterdam UMC or Antoni van Leeuwenhoek cancer hospital were studied. Myelotoxicity and nephrotoxicity were defined based on common terminology criteria (CTCAE v4.03) and categorized as $\geq$ grade 1 and $\geq$ grade 2 . Modified Poisson regression and Cox proportional hazards model were used to estimate relative risks and cumulative hazard respectively.

Results: Of the 115 NSCLC patients receiving DLD ( $N=62)$ and $C H D(N=53), 60 \%$ had zgrade 1 anemia, 33.9\% leukopenia, 31.3\% neutropenia, 27.8\% thrombocytopenia, $32.2 \%$ acute nephrotoxicity with combined definition (Cr-electrolyte nephrotoxicity), and $58.3 \%$ chronic nephrotoxicity. The DLD group was older, had an earlier cancer stage, had more comorbidities, and had higher baseline albumin levels. In the DLD group less $\geq$ grade 2 toxicities were reported compared to the CHD group except for Cr-electrolyte nephrotoxicity. However, there was a stronger association in the DLD group with zgrade 1 leukopenia, thrombocytopenia, and Cr-electrolyte nephrotoxicity. The DLD group developed significantly more $\geq$ grade 1 leukopenia [adjusted relative risk $(\operatorname{adj} R R)=1.83,95 \% \mathrm{Cl} 1.02-3.27]$, thrombocytopenia (adjRR=3.43, 95\% Cl 1.64-7.15), and $\geq$ grade 2 Cr-electrolyte nephrotoxicity (adjRR=3.02, 95\% Cl 1.20-7.56). The DLD 
group had a lower adjusted cumulative hazard for developing $\geq$ grade 2 myelotoxicity and chronic nephrotoxicity but not for Cr-electrolyte nephrotoxicity [adjusted hazard ratio $(\operatorname{adjHR})=3.90,95 \% \mathrm{Cl} 1.35-11.23]$. In contrast, DLD showed protective effect to $\geq$ grade 2 nephrotoxicity when definition was restricted to the traditional creatinine-based definition (adjRR=0.07, 95\% Cl 0.01-0.86; adjHR=0.05, 95\% Cl 0.01-0.56).

Conclusions: Overall, the DLD regimen was safer than the $\mathrm{CHD}$ regimen when assessing the risk of $\geq$ grade 2 myelotoxicity and nephrotoxicity. However, this might not be the case in patients with a higher risk of electrolyte abnormalities.

Keywords: cisplatin, low dose, radiotherapy, myelotoxicity, bone marrow suppression, nephrotoxicity, toxicity

\section{INTRODUCTION}

Cisplatin is the current first line of treatment in locally advanced non-small cell lung cancer (NSCLC); (Vansteenkiste et al., 2013; Besse et al., 2014; Fennell et al., 2016) it acts by creating DNA cross-links that, after failed DNA repair, lead to cell apoptosis (Dilruba and Kalayda, 2016). Cisplatin sensitivity and resistance are patient dependent (Rose et al., 2014), and cisplatin can cause multiple side effects including ototoxicity, nephrotoxicity, and myelotoxicity (Hartmann and Lipp, 2003). A new generation of drugs, including carboplatin and oxaliplatin, is currently available on the market as well. While these drugs reduce the risk of neurotoxicity and ototoxicity, they are known to increase myelotoxicity and are less effective in improving overall survival (Dilruba and Kalayda, 2016). Therefore, despite these new developments, cisplatin is still the standard treatment for lung cancer (Vansteenkiste et al., 2013; Besse et al., 2014). The major dose-limiting toxicities of cisplatin are nephrotoxicity and myelotoxicity. The severity of nephrotoxicity is directly proportional to the amount of cisplatin accumulation taking place in the kidneys (Moon et al., 2011). Nephrotoxicityindicated by high serum creatinine, low estimated glomerular filtration rate (eGFR), and/or electrolyte abnormalities, appears in about one-third of cisplatin treated patients although percentage may be higher in elderly and children (Pabla and Dong, 2008; Zazuli et al., 2018). Myelotoxicities appear in 16$40 \%$ of the patients treated with cisplatin, of which leukocytopenia and neutropenia have the highest incidence (Atmaca et al., 2013; Yu et al., 2015).

Two different forms of cisplatin-based regimens are known to be used in the management of NSCLC: the standard regimencyclic high-dose (CHD) cisplatin and the alternative regimendaily low-dose (DLD) cisplatin regimen with concurrent radiotherapy where cisplatin acts as a radiosensitizer. The current standard, CHD regimen, is chemotherapy, or sequential chemoradio therapy, of two to four cycles with a three to 4 week interval between chemotherapy cycles, each cycle receiving a relatively high cisplatin dose of $75-80 \mathrm{mg} / \mathrm{m}^{2}$

\footnotetext{
Abbreviations: adjRR, adjusted relative risk; adjHR, adjusted hazard ratio; AKI, acute kidney injury; CHD, cyclic high-dose cisplatin; CKD, chronic kidney disease; CTCAE, common terminology criteria for adverse events; DLD, daily low-dose cisplatin; eGFR, estimated glomerular filtration rate; SCr, serum creatinine.
}

(Vansteenkiste et al., 2013; Besse et al., 2014). An alternative regimen, the DLD regimen, is often used in patients with multiple comorbidities. This regimen includes daily low-dose cisplatin $\left(6 \mathrm{mg} / \mathrm{m}^{2}\right)$ with concurrent radiotherapy (up to $66 \mathrm{~Gy}$, divided in $24 \times 2.75$ Gy) (Milano et al., 1990; SchusterUitterhoeve et al., 1996). The DLD regimen was shown to have similar efficacy compared to the standard treatment regimen (Takata et al., 2002; Uitterhoeve et al., 2007; Kappers et al., 2011; van Diessen et al., 2016). Furthermore, DLD therapy has a similar, possibly more favorable, radiotoxicity profile, as compared to the highly toxic concurrent high-dose therapy (Biedermann et al., 2000; Belderbos et al., 2007; Uitterhoeve et al., 2007; Kappers et al., 2011).

While other studies have compared the effectiveness and overall safety between both regimens (Belderbos et al., 2007; Uitterhoeve et al., 2007), none have compared DLD and CHD to investigate specific differences in risk for myelotoxicity and nephrotoxicity. Such comparison could provide information needed to support personalized therapy in NSCLC patients.

Thus, we aimed to assess if the occurrence, severity, and time to the development of myelotoxicity and nephrotoxicity differed between patients receiving a DLD regimen and those receiving a $\mathrm{CHD}$ regimen. We hypothesized that the DLD regimen is safer than CHD regimen. This study could provide new insights for cisplatin risk management in NSCLC patients, hopefully improving the patients' quality of life during and after treatment by minimizing the adverse events without compromising efficacy by applying more personalized treatment.

\section{METHODS}

\section{Study Design and Population}

We conducted a retrospective cohort study. NSCLC patients were treated with the DLD and CHD regimen at the Amsterdam UMC tertiary care center [location Academic Medical Center (AMC) and Vrije Universiteit medical center (VUMC), between January 2016 and June 2018] or with DLD at the Antoni van Leeuwenhoek cancer hospital (the Netherlands Cancer Institute, between January and 2011 and August 2012) (Uyterlinde et al., 2014). These time windows were selected to ensure uniformity of DLD treatment in terms of prehydration protocol between both 
centers. To our knowledge, no consistent evidence confirmed the effect of cancer clinical staging to chemotherapy toxicity, especially cisplatin. Thus, we included all patients receiving the two regimens regardless the clinical stage. Patients with an adapted diagnosis of small cell lung cancer (SCLC) or another primary malignancy were excluded.

Cohort entry was defined as the first day of cisplatin treatment. Patients were followed until the date of the adverse event, lost-to-follow-up (treatment discontinuation and/or switching), or the study end date, i.e., 90 days after the last administration of cisplatin to allow for reporting of lagged adverse drug effects, whichever occurred first.

The ethics committee of AMC, has evaluated the protocol (W18_003 \# 18.014) and stated that this study was outside the boundaries of the Medical Research Involving Human Subjects Act (WMO).

\section{Data Collection}

The following data was extracted from the electronic patient record: age at start of treatment (years); gender; ethnicity; body mass index $\left(\mathrm{BMI}, \mathrm{kg} / \mathrm{m}^{2}\right)$; body surface area $\left(\mathrm{BSA}, \mathrm{m}^{2}\right)$; cancer stage (I-IV); histology of lung cancer (adeno; squamous; large cell; other); Karnofsky performance status (KPS, score); World Health Organization performance status (WHO PS); date of treatment start; type and dose $\left(\mathrm{mg} / \mathrm{m}^{2}\right)$ of chemotherapy received; pretreatment received; amount of hydration received; treatment completion; date of last follow-up; number of chronic comorbidities. Furthermore, we collected lab values at baseline, throughout treatment duration (every week at day 5 for DLD and every cycle 1 day before CHD administration), at the end of treatment, and at 90 days after the last administration of chemotherapy. The following lab values were recorded: creatinine (mg/dl); eGFR by applying Chronic Kidney DiseaseEpidemiology Collaboration (CKD-EPI) equation ( $\mathrm{ml} / \mathrm{min} /$ $\left.1.73 \mathrm{~m}^{2}\right)$; magnesium $(\mathrm{mg} / \mathrm{dl})$; potassium $(\mathrm{mEq} / \mathrm{L})$; phosphate (mg/dl); albumin (g/dl); bilirubin (mg/dl); hemoglobin ( $\mathrm{g} / \mathrm{dl})$; leukocytes (cells $/ \mathrm{mm}^{3}$ ); neutrophils (cells $/ \mathrm{mm}^{3}$ ); and thrombocytes $\left(\right.$ cells $\left./ \mathrm{mm}^{3}\right)$.

\section{Outcomes}

Primary endpoints were cisplatin-related toxicity such as the development of myelotoxicity and nephrotoxicity during the follow-up period. Myelotoxicity consisted of anemia, leukopenia, neutropenia, and thrombocytopenia. Nephrotoxicity consisted of acute nephrotoxicity with combined definition (serum electrolytes and creatinine-based acute kidney injury; Cr-electrolyte nephrotoxicity) and chronic nephrotoxicity (eGFR-based chronic kidney disease). Each toxicity was graded according to the common terminology criteria of adverse events (CTCAE v4.3) (NCI, 2010), for which the criteria of acute nephrotoxicity consisted of the combined criteria of acute kidney injury and electrolyte disorders (hypomagnesemia, hypokalemia, hypophosphatemia) to increase sensitivity of detecting renal tubular injury caused by cisplatin. Beside using modified acute nephrotoxicity definition, we also analyzed the traditional serum creatinine-based acute nephrotoxicity (SCr-AKI) and electrolyte abnormalities separately. We did not collect urine volume data since it was not required by CTCAE criteria. Two cut-offs for adverse events grades were used: $\geq$ grade 1 (overall toxicities) vs. no toxicity and $\geq$ grade 2 (moderate-to-severe toxicities) $v s$. no toxicity and grade 1 (mild toxicities). Our secondary endpoint was the kidney function trend marked by change in eGFR over time. Blood tests provided objective measurement and were routinely measured and documented in the clinics. Thus, our investigation focused on myelotoxicity and nephrotoxicity. Although very relevant, other cisplatin-related toxicities e.g., nausea/vomit and neurotoxicity were not regularly measured, making it more susceptible to bias in the setting of such retrospective study.

\section{Treatment}

The DLD group treatment plan was specified as receiving $6 \mathrm{mg} / \mathrm{m}^{2}$ of cisplatin for 24 days (24 administrations, 5 times per week), while also receiving intensity modulated radiotherapy up to 66 Gy ( $24 \times 2.75$ Gy) 1-2 h after cisplatin administration, the standard low-dose regimen in the hospital. The CHD treatment plan was specified as receiving $30-80 \mathrm{mg} / \mathrm{m}^{2}$ cisplatin-based chemotherapy for a three to 4 week interval for $2-3$ cycles in combination with pemetrexed $\left(500 \mathrm{mg} / \mathrm{m}^{2}\right)$, etoposide $\left(100 \mathrm{mg} / \mathrm{m}^{2}\right)$, docetaxel $\left(75 \mathrm{mg} / \mathrm{m}^{2}\right)$, or gemcitabine $\left(1.250 \mathrm{mg} / \mathrm{m}^{2}\right)$.

\section{Confounders and Covariates}

The possible confounders that were used as covariates in our models were identified based on directed acyclic graphs (Textor et al., 2016) and were different for each study outcome (Figure 1). Age at treatment and gender were covariates for all outcomes (Hardy et al., 2010) except for chronic nephrotoxicity as those variables were already taken into account when calculating individual eGFR. Additional covariates for myelotoxicity were as follows: number of comorbidities, and any of the following baseline disease states as defined by blood cell counts; anemia by hemoglobin, leukopenia by leukocytes, neutropenia by neutrophils, thrombocytopenia by platelets (Moreau et al., 2009; Hardy et al., 2010; Castelan-Martinez et al., 2016; Nishikawa et al., 2017). Number of comorbidities, baseline serum creatinine, albumin, magnesium, phosphate, and potassium were included for Cr-electrolyte nephrotoxicity while baseline albumin and eGFR were covariates for chronic nephrotoxicity (Kidera et al., 2014; Yamamoto et al., 2017). Unlike Cr-electrolyte nephrotoxicity, SCr-AKI was not corrected for baseline electrolyte values while electrolyte abnormalities weren't corrected for baseline serum creatinine.

\section{Statistical Analysis}

Missing values were analyzed before conducting multiple imputation. Multiple imputations $(\mathrm{N}=5)$ were used to address missing data in baseline laboratorium values: albumin $(13.04 \%$ missing values), serum creatinine $(0.87 \%)$, magnesium $(47.83 \%)$, potassium $(6.09 \%)$, hemoglobin $(1.74 \%)$, leukocyte $(0.87 \%)$, neutrophil (16.52\%), platelet (1.74\%).

Modified Poisson regression models (Zou, 2004) were used to estimate relative risks (RR) comparing the DLD and CHD treatment groups for different outcome cut-offs ( $\geq$ grade 1 


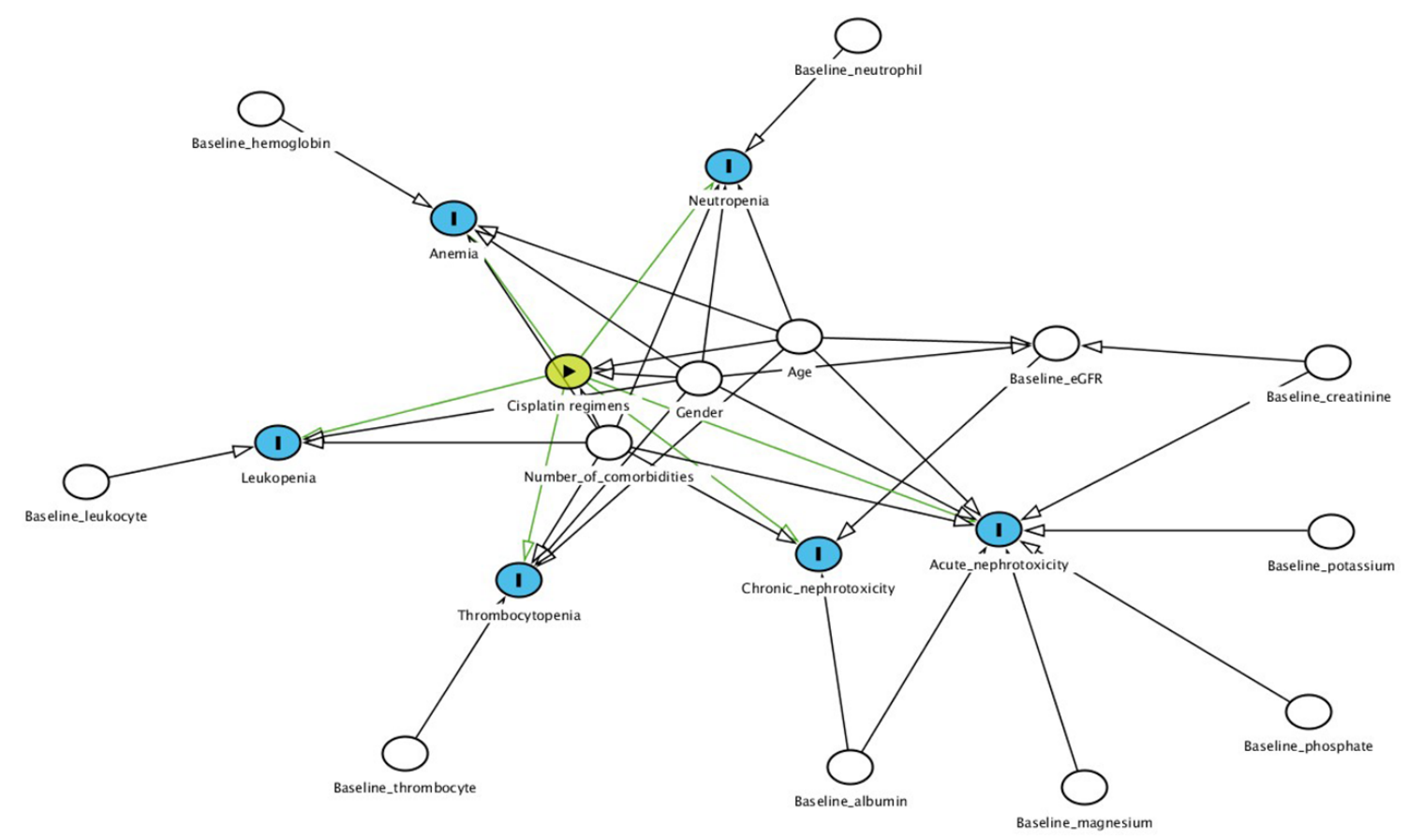

FIGURE 1 | Directed acyclic graphs of covariates included in this study.

and $\geq$ grade 2 toxicities) adjusted for measured confounders and covariates. We used a generalized estimating equations (GEE) approach to the linear model to compare eGFR from baseline, at the end of treatment and 90 days after the last administration of cisplatin between both treatment regimen, adjusted for number of comorbidity and baseline albumin.

A time-to-event analysis was performed in order to assess whether the time to toxicity development differed between regimens. Only moderate-to-severe adverse events were analyzed to capture clinically relevant adverse events. The Cox proportional hazards model with time frame 120 days after the start of treatment was used to estimate cumulative hazard on occurrence of an event over time (HR) due to differences in treatment duration between groups, adjusting for the same covariates as the modified Poisson regression models. To test the appropriateness of selecting 120 dayscut off, we compared occurrence of first toxicity before and after 120 days since the start of treatment in both treatment arms. The proportional hazards assumption was verified visually by comparing Kaplan-Meier curves of both treatment arm. All statistical analysis was performed with SPSS (version 25; SPSS Inc., Chicago, IL).

\section{RESULTS}

\section{Subject Characteristics}

Between January 2016 and June 2018, 86 patients were treated with cisplatin chemotherapy for the indication of non-small cell lung cancer at the Amsterdam UMC: 22 with DLD and 64 with
CHD, 49 at location AMC and 37 at location VUmc. In total, 40 DLD cisplatin-treated patients from the Netherlands Cancer Institute between January and 2011 and August 2012 were included in the analysis (Figure 2). There were no significant

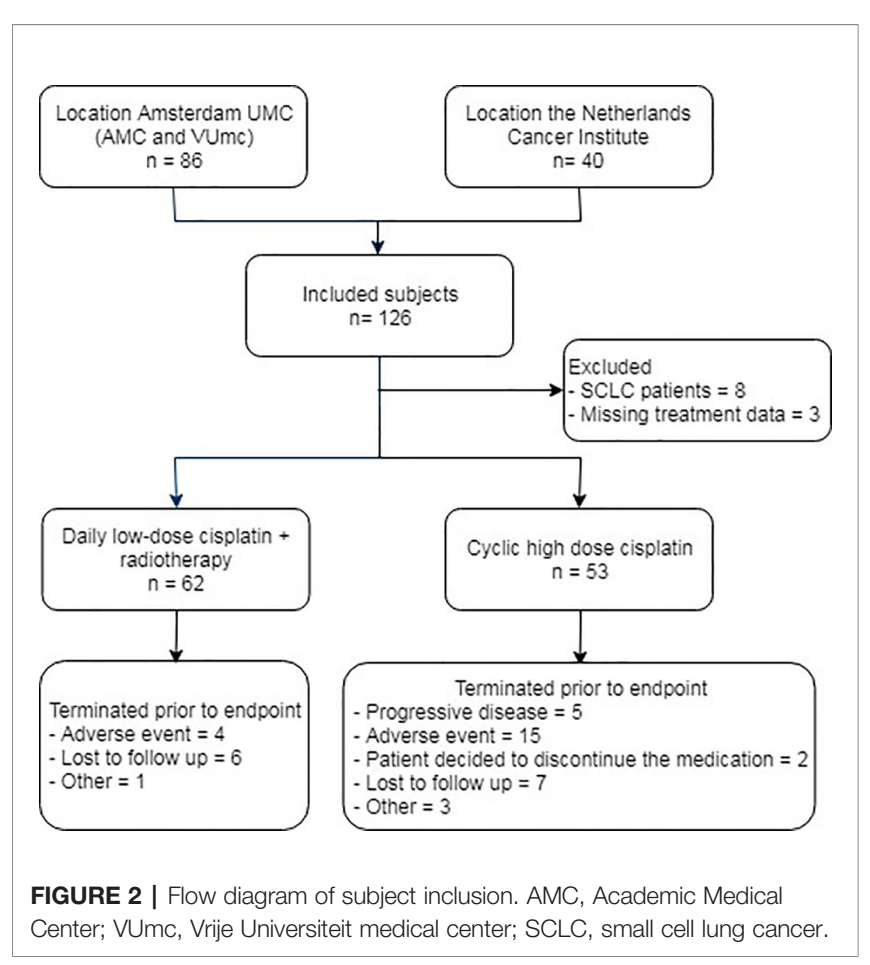


differences in clinical characteristics between DLD-treated patients from Amsterdam UMC and the Netherlands Cancer Institute except in performance status (functional impairment). Overall, patients at the Netherlands Cancer Institute had a better performance status; $67.6 \%$ had a WHO performance status of 0 , compared to only $36 \%$ of the patients treated at Amsterdam UMC (Table S1). In total 11 patients were excluded from the study: eight patients had an indication of small cell lung cancer (SCLC) and for three patients complete treatment data was lacking. Of the remaining 115 patients, 62 received DLD

TABLE 1 | Patient's characteristics for non-small lung cancer patients treated with cisplatin, split between the daily low-dose and the cyclic high-dose treatment group.

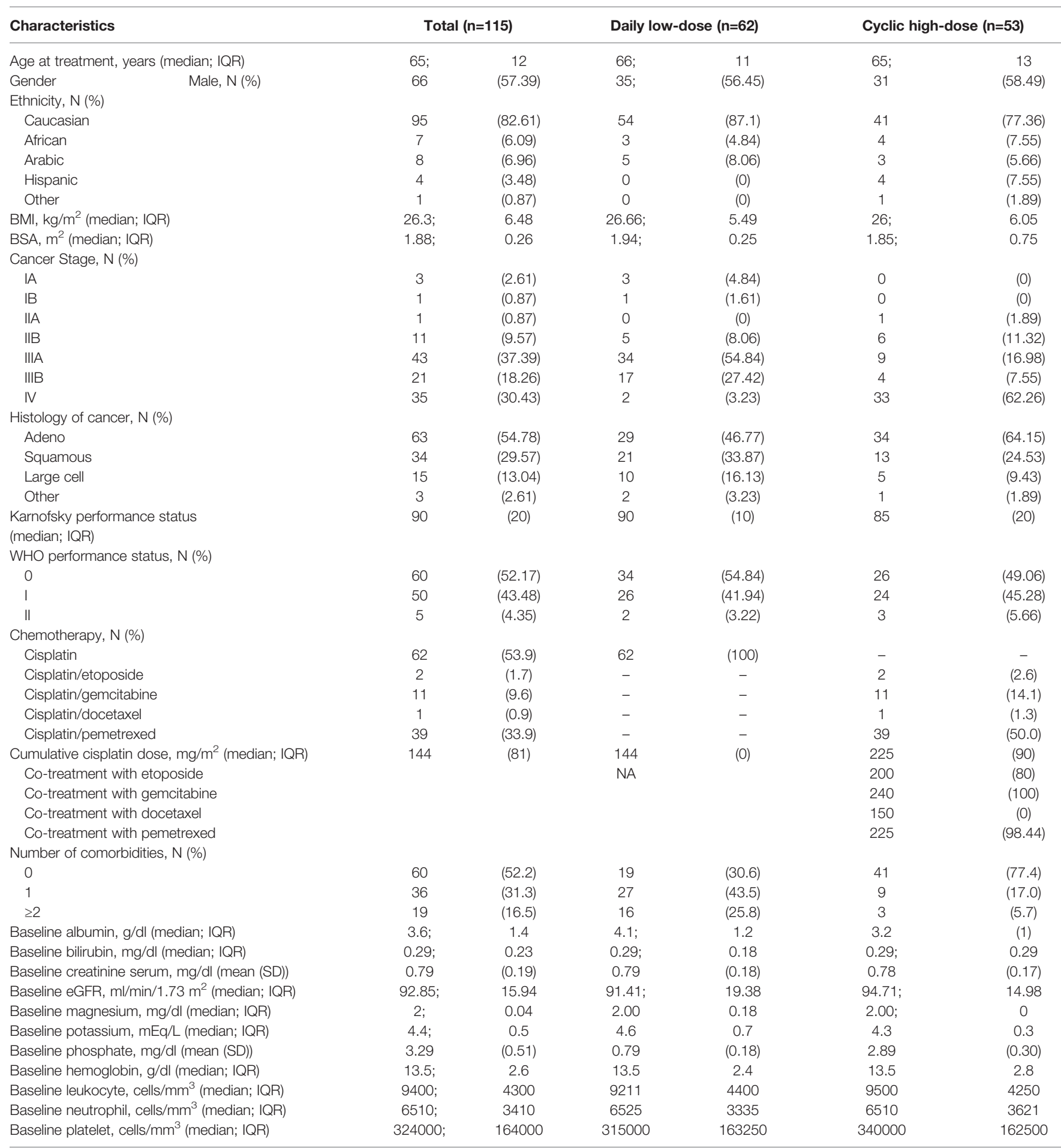

BMI, body mass index; BSA, body surface area; WHO, World Health Organization; IQR, interquartile range). 
cisplatin with concurrent chemo radiotherapy, 53 received a CHD cisplatin therapy. In total, 43 out of 115 patients did not complete treatment and follow-up due to various reasons (Figure 2). In the DLD treatment group, four patients did not continue treatment due to an adverse event, six were lost to follow-up, and one had another unknown reason for not reaching the end date. From the $\mathrm{CHD}$ treatment group there were 5 patients who did not continue cisplatin treatment due to progressive disease, 15 who did not continue treatment due to an adverse event, 2 refused further medication, 7 were lost to followup, and 3 had another unknown reason for not reaching the end date.

Patient characteristics of the total population, stratified by receiving DLD treatment or CHD treatment, are shown in Table $\mathbf{1}$. As compared to the CHD group, the DLD group was older, received less cumulative cisplatin dose, had an earlier cancer stage, had more comorbidities, and had higher baseline albumin levels. On the other side, the CHD treatment group had higher baseline eGFR, baseline phosphate levels, baseline numbers of leukocyte and platelets, and always received combination chemotherapy, including cisplatin combined with etoposide, gemcitabine, docetaxel, or pemetrexed.

\section{Development of Myelotoxicity and Nephrotoxicity}

When applying $\geq$ grade 1 criteria as a cut-off point for developing toxic events, the most common toxic events reported during treatment were: anemia (60\%), leukopenia (33.9\%), neutropenia (31.3\%), thrombocytopenia (27.8\%), Cr-electrolyte nephrotoxicity $(32.2 \%)$, SCr-AKI (12.2\%), electrolyte abnormalities (23.5\%), and chronic nephrotoxicity (58.3\%). When we used $\geq$ grade 2 as the cut-off point, toxic events were reduced to $23.5 \%$ for anemia, $20.0 \%$ for leukopenia, $13.9 \%$ for neutropenia, $7.0 \%$ for thrombocytopenia, $27.8 \%$ for $\mathrm{Cr}$ electrolyte nephrotoxicity, $6.1 \%$ for SCr-AKI, and $20.9 \%$ for chronic nephrotoxicity while electrolyte normalities proportion did not change.

The proportions of $\geq$ grade 1 toxicities were higher in DLD group except for anemia (53.2 vs. 67.9\%), neutropenia (24.2 vs. $39.6 \%$ ), and SCr-AKI (8.1 vs. 16.9\%). However, the proportion of $\geq$ grade 2 toxicities were lower in the DLD group except for thrombocytopenia (8.1 vs. 5.7\%), Cr-electrolyte nephrotoxicity (38.7 vs. 15.1\%), and electrolyte abnormalities (37.1 vs. 5.7\%).

\section{Treatment Regimen as Predictor for Myelotoxicity and Nephrotoxicity}

The proportion of patients that developed overall ( $\geq$ grade 1 ) and moderate-to-severe ( $\geq$ grade 2 ) adverse events for each treatment arm can be found in Table 2 . The most frequent $\geq$ grade 1 and $\geq$ grade 2 adverse events in DLD group were chronic nephrotoxicity (64.5\%) and Cr-electrolyte nephrotoxicity (38.7\%). For CHD group, the most frequent $\geq$ grade 1 and $\geq$ grade 2 adverse events in DLD group were anemia (67.9 and 35.8\%, respectively). The adjusted RRs for $\geq$ grade 1 leukopenia [adjusted relative risk (adjRR) 1.83, 95\% CI 1.02-3.27], and specifically thrombocytopenia (adjRR 3.43, 95\% CI 1.64-7.15) were higher for the DLD group than the CHD group. As compared to the CHD group, the adjusted relative risk (adjRR) for $\geq$ grade 2 neutropenia occurrence in the DLD group was lower (adjRR 0.41, 95\% CI 0.17-0.98). Overall, as compared to the CHD group, the DLD group had a lower risk of having $\geq$ grade 2 myelotoxicities (Figure 3). However, DLD had a higher risk with $\geq$ grade 1 leukopenia and thrombocytopenia, suggesting that patients receiving the DLD regimen had a higher incidence of mild leukopenia and thrombocytopenia compared with patients receiving the $\mathrm{CHD}$ regimen.

TABLE 2 | Occurrence of myelotoxicity and nephrotoxicity per treatment group and relative risk of daily low-dose cisplatin (DLD) compatred to cyclic high-dose cisplatin (CHD) for each toxicity.

\begin{tabular}{|c|c|c|c|c|c|c|c|c|}
\hline \multirow{2}{*}{$\begin{array}{l}\text { Toxicities } \\
\text { Anemia }\end{array}$} & \multirow{3}{*}{$\begin{array}{l}\geq \text { Grade } 1 \\
\geq \text { Grade } 2\end{array}$} & \multicolumn{2}{|c|}{ DLD (n=62) } & \multicolumn{2}{|c|}{ CHD (n=53) } & \multirow{2}{*}{$\frac{\operatorname{adjRR}^{\mathrm{a}, \mathrm{b}}}{0.96}$} & \multicolumn{2}{|c|}{$95 \% \mathrm{Cl}$} \\
\hline & & 33 & $53.2 \%$ & 36 & $67.9 \%$ & & 0.69 & 1.33 \\
\hline & & 8 & $12.9 \%$ & 19 & $35.8 \%$ & 0.57 & 0.24 & 1.37 \\
\hline \multirow[t]{2}{*}{ Leukopenia } & $\geq$ Grade 1 & 26 & $41.9 \%$ & 13 & $24.5 \%$ & 1.83 & 1.02 & 3.27 \\
\hline & $\geq$ Grade 2 & 11 & $17.7 \%$ & 12 & $22.6 \%$ & 0.57 & 0.24 & 1.33 \\
\hline \multirow[t]{2}{*}{ Neutropenia } & $\geq$ Grade 1 & 15 & $24.2 \%$ & 21 & $39.6 \%$ & 0.55 & 0.29 & 1.06 \\
\hline & $\geq$ Grade 2 & 5 & $8.1 \%$ & 11 & $20.8 \%$ & 0.41 & 0.17 & 0.98 \\
\hline \multirow[t]{2}{*}{ Thrombocytopenia } & $\geq$ Grade 1 & 25 & $40.3 \%$ & 7 & $13.2 \%$ & 3.43 & 1.64 & 7.15 \\
\hline & $\geq$ Grade 2 & 5 & $8.1 \%$ & 3 & $5.7 \%$ & 0.71 & 0.21 & 2.42 \\
\hline \multirow[t]{2}{*}{ Cr-electrolyte nephrotoxicity } & $\geq$ Grade 1 & 23 & $37.1 \%$ & 14 & $26.4 \%$ & 1.96 & 1.06 & 3.62 \\
\hline & $\geq$ Grade 2 & 24 & $38.7 \%$ & 8 & $15.1 \%$ & 3.02 & 1.20 & 7.56 \\
\hline \multirow[t]{2}{*}{ SCr-AKI } & $\geq$ Grade 1 & 5 & $8.1 \%$ & 9 & $16.9 \%$ & 0.56 & 0.18 & 1.76 \\
\hline & $\geq$ Grade 2 & 1 & $1.6 \%$ & 6 & $11.3 \%$ & 0.07 & 0.01 & 0.86 \\
\hline \multirow[t]{2}{*}{ Electrolyte abnormalities } & $\geq$ Grade 1 & 20 & $32.3 \%$ & 7 & $13.2 \%$ & 2.64 & 1.20 & 5.80 \\
\hline & $\geq$ Grade 2 & 23 & $37.1 \%$ & 3 & $5.7 \%$ & 8.38 & 2.44 & 28.81 \\
\hline \multirow[t]{2}{*}{ Chronic nephrotoxicity } & $\geq$ Grade 1 & 40 & $64.5 \%$ & 27 & $50.9 \%$ & 1.64 & 0.92 & 2.90 \\
\hline & $\geq$ Grade 2 & 9 & $14.5 \%$ & 15 & $28.3 \%$ & 0.39 & 0.08 & 1.93 \\
\hline
\end{tabular}

Toxicity recorded as mild toxicity (grade $\geq 1$ ) and moderate-to-severe toxicity (grade $\geq 2$ ).

aModified Poisson regression was conducted by including adjustment for confounder and covariates. All outcomes were adjusted for age at treatment and gender except for chronic nephrotoxicity. Myelotoxicity outcome were adjusted for age at treatment, gender, number of comorbidities, and any of the following baseline disease states as defined by blood cell

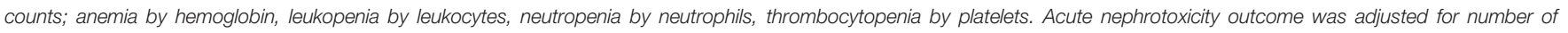
comorbidities, baseline serum creatinine, albumin, magnesium, phosphate, and potassium while chronic nephrotoxicity was adjusted for baseline albumin and eGFR.

${ }^{b} \mathrm{CHD}$ regimen was the reference group for each toxicity analysis. 


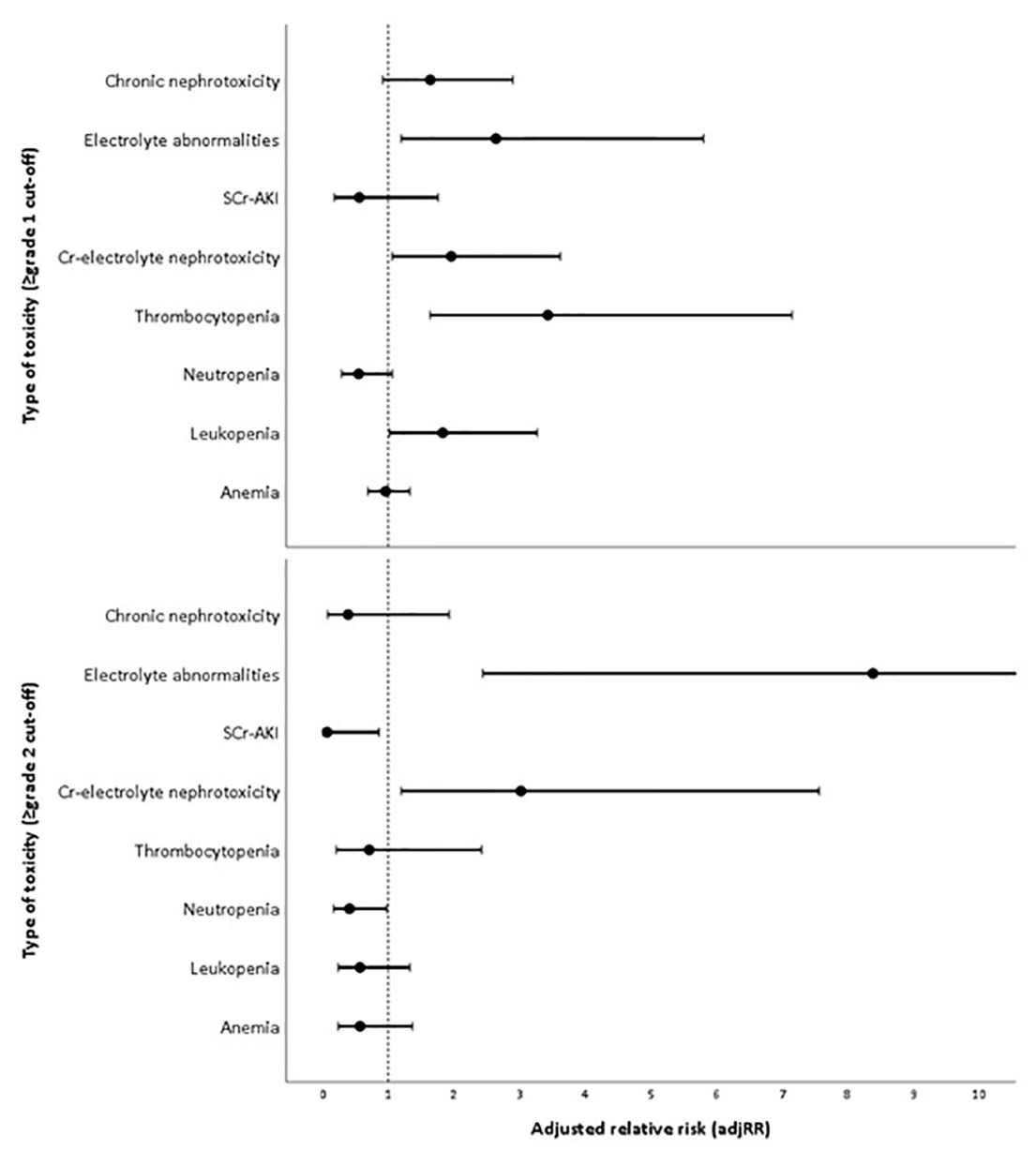

FIGURE 3 | Adjusted risk of each toxicity in daily low-dose cisplatin (DLD) group compared to cyclic high-dose cisplatin (CHD) group in two cut-offs ( $\geq$ grade 1 and zgrade 2).

The proportion of patients developing $\geq$ grade 1 nephrotoxicity for the DLD and CHD group was 37.1-64.5\% and $26.4-50.9 \%$ respectively, and the incidence of moderate-tosevere nephrotoxicity was $14.5-38.7 \%$ and $15.1-28.3 \%$ respectively. Adjusted risk for Cr-electrolyte nephrotoxicity, either using $\geq$ grade 1 or $\geq$ grade 2 cut-offs, were higher on DLD arm (adjRR 1.96, 95\% CI 1.06-3.62 and adjRR 3.02, 95\% CI 1.20-7.56). The risk of SCr-AKI was lower in DLD than in CHD arm ( $\geq$ grade 1 : adjRR $0.56,95 \%$ CI $0.18-1.76$; $\geq$ grade 2 : adjRR 0.07, 95\% CI 0.01-0.86) when we differentiated between AKI-SCr and electrolyte abnormalities, suggesting that the risk on electrolyte abnormalities was substantially higher in the DLD than in the CHD arm. The adjusted risk for $\geq$ grade 1 chronic nephrotoxicity was higher on DLD group as well (adjRR 1.64, 95\% CI 0.92-2.90). However, the adjusted risk was lower when using $\geq$ grade 2 cut-offs (adjRR 0.39, 95\% CI 0.08-1.93). Overall, as compared to the CHD group, the DLD group had a higher risk on developing nephrotoxicities except for $\geq$ grade 2 chronic nephrotoxicity (Figure 3).

From the Kaplan-Meier curve (Figures 4 and 5), we observed that the DLD group had a lower risk of $\geq$ grade 2 toxicity than CHD except for Cr-electrolyte nephrotoxicity and electrolyte abnormalities. The results from time-to-event analysis also confirmed that patients from the DLD group had a lower hazard on having zgrade 2 toxicity except for Cr-electrolyte nephrotoxicity [adjusted hazard ratio (adjHR) 3.90, 95\% CI 1.35-11.23] and electrolyte abnormalities (adjHR 17.40, CI 95\% 3.04-99.71) (Table 3). In addition, we found no statistically significant differences in occurrence of first toxicity before and after 120 days since the start of treatment in both treatment arms (Table 4) proofing that selecting 120 days cut-off for Cox proportional hazard model was appropriate.

As for the secondary endpoint, the reduction in eGFR from baseline was less in the DLD compared to the CHD group $(\beta=8.49$, 

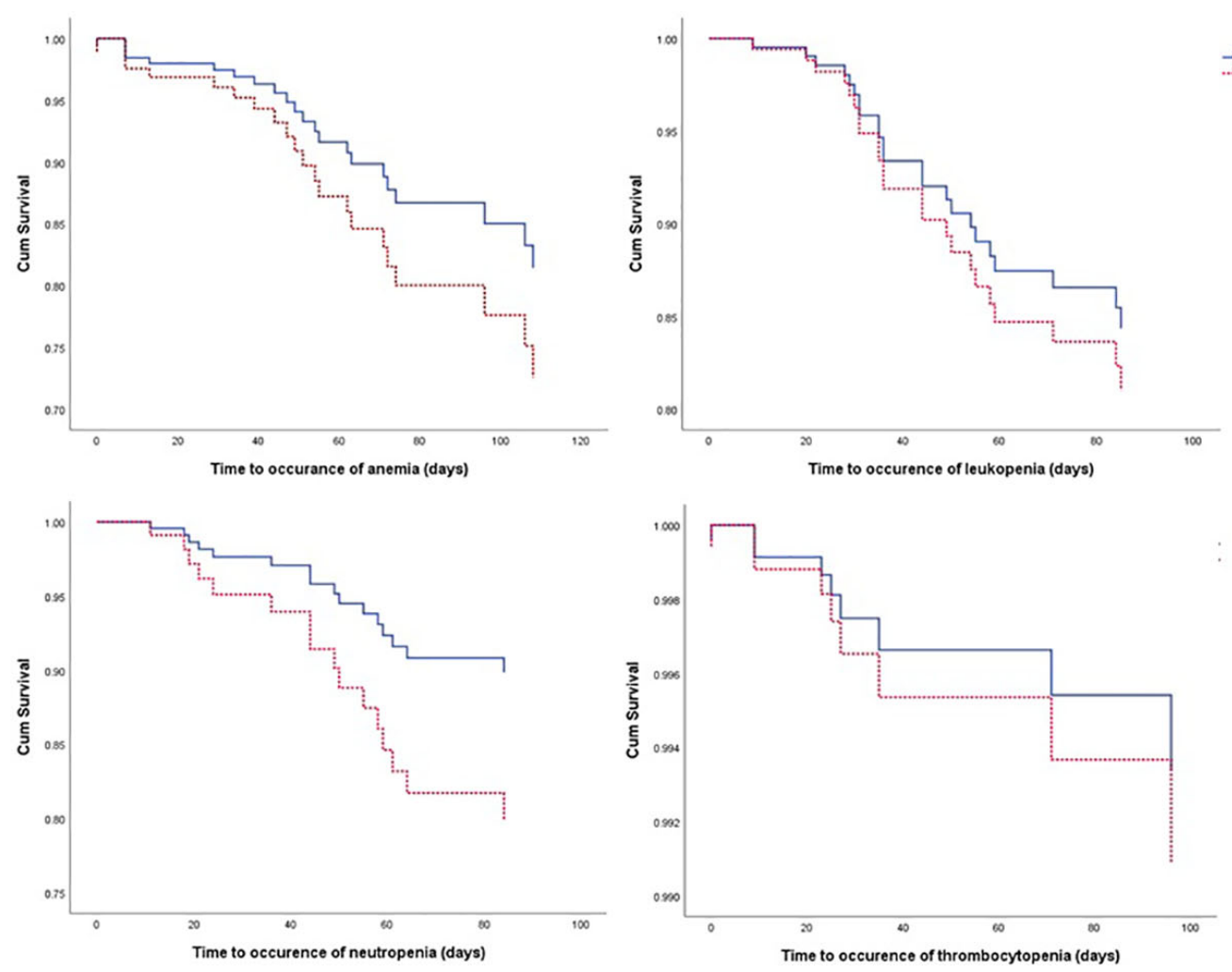

FIGURE 4 | The Kaplan-Meier curve of daily low-dose cisplatin (DLD) and cyclic high-dose cisplatin (CHD) treatment group on $\geq$ grade 2 myelotoxicity during 120 days of observation. Cum survival, cumulative survival.

95\% CI 1.86-15.13), indicating a potential protective effect with respect to the occurrence of chronic kidney disease (Table 5).

\section{DISCUSSION}

Cisplatin may cause many types of toxicity, including myelotoxicity, acute, and chronic nephrotoxicity accompanied by electrolyte abnormalities (Hartmann and Lipp, 2003). In this study we compared the risk of myelotoxicity and nephrotoxicity between two cisplatin treatment regimens which differed in the height and frequency of dosing: the DLD and CHD regimen. We demonstrated that the DLD regimen led to higher risk on $\geq$ grade 1 leukopenia, thrombocytopenia, Cr-electrolyte and chronic nephrotoxicity and electrolyte abnormalities but lower on risk on anemia, neutropenia, and SCr-AKI as compared to the CHD regimen. However, when we considered the more severe adverse drug reactions ( $\geq$ grade 2 ), the DLD regimen led to lower risk on all toxicities except Cr-electrolyte nephrotoxicity and electrolyte abnormalities based on time-to-event analysis. Thus, both the high dosing frequency in the DLD regimen and the high dose in the CHD regimen affect the toxicity profile of cisplatin treatment.

Our findings are in line with a previous randomized controlled trial comparing sequential ( $\mathrm{CHD}$ cisplatin plus gemcitabine) versus concurrent chemo-radiotherapy (DLD cisplatin plus radiotherapy) in 142 patients with inoperable NSCLC (Belderbos et al., 2007). Belderbos et al. demonstrated that the proportion of patients experiencing thrombocytopenia, leukopenia, and granulocytopenia ( $\geq$ grade 3 ) was smaller when treated with DLD compared to the CHD regimen. However, the occurrence of treatment-related kidney toxicity was not investigated. In contrast, a non-randomized trial in 131 Dutch patients showed slightly higher incidence of severe late toxicity in DLD group compared to CHD (27 vs. 23\% respectively) (Uitterhoeve et al., 2007). However, the type of toxicity of both arms was not reported in detail in this study, making it difficult to compare different type of toxicity occurred in both regimen.

Compared to the CHD arm, we found that patients in the DLD arm were more likely to experience electrolyte imbalance but were less likely to develop nephrotoxicity (marked by high serum creatinine and low eGFR) compared to CHD arm. We could not find evidence from human or in vitro studies using human cell-lines explaining the underlying mechanisms. However, according to a preclinical study in rodents, this might be related to the observation of a low cleaved caspase- 3 level as a measure of apoptosis, a low level of tubular necrosis, low interleukin (IL)-6 messenger RNA (mRNA) levels (a proinflammatory cytokine that has been found in kidney injury), but 

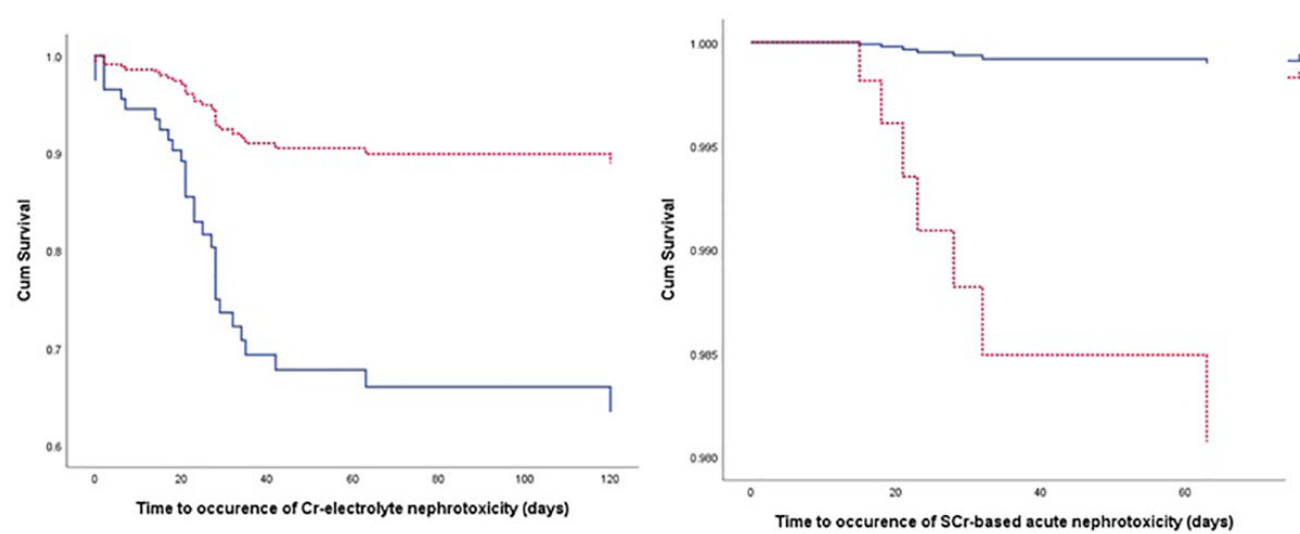

Study arm

Thasly lowdose treatment
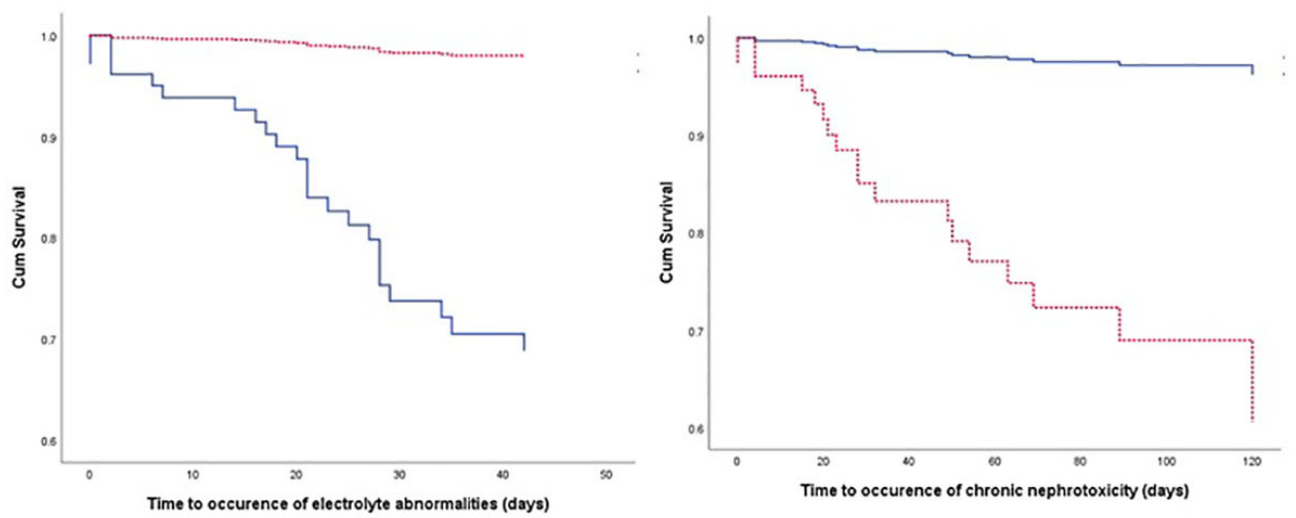

FIGURE 5 | The Kaplan-Meier curve of daily low-dose cisplatin (DLD) and cyclic high-dose cisplatin (CHD) treatment group on $\geq$ grade 2 nephrotoxicity and electrolyte abnormalities during 120 days of observation. Cum survival, cumulative survival.

TABLE 3 | Hazard ratio of moderate-to-severe ( $\geq$ grade 2 ) myelotoxicity and nephrotoxicity of daily low-dose cisplatin compared to cyclic high-dose cisplatin.

\begin{tabular}{lccc}
\hline Adverse events & adjHR $^{\mathbf{a}}$ & \multicolumn{2}{c}{$\mathbf{9 5 \%} \mathbf{~ C l}$} \\
\hline Anemia & 0.64 & 0.20 & 2.03 \\
Leukopenia & 0.81 & 0.27 & 2.42 \\
Neutropenia & 0.48 & 0.14 & 1.65 \\
Thrombocytopenia & 0.72 & 0.04 & 12.20 \\
Cr-electrolyte nephrotoxicity & 3.90 & 1.35 & 11.23 \\
SCr-AKl & 0.05 & 0.01 & 0.56 \\
Electrolyte abnormalities & 17.40 & 3.04 & 99.71 \\
Chronic nephrotoxicity & 0.05 & $<0.01$ & 2.59 \\
\hline
\end{tabular}

${ }^{a}$ Cox regression was conducted by including adjustment confounder and covariates mentioned at Methods section.

Cyclic high-dose was the reference category.

a significant increase in infiltrating macrophages who play role in repair response post-injury in a high-frequency low-dose cisplatin regimen (Sharp et al., 2016). To conclude, cell death through apoptosis and necrosis was lower in mice subjected to the high-frequency low-dose cisplatin regimen (Sharp et al., 2016). This is in line with the decreased risk of serum creatinine based nephrotoxicity and eGFR in the DLD group as demonstrated in this study.
TABLE 4 | Comparison of first toxicity events occurred before and after 120 days of treatment.

\begin{tabular}{llccc}
\hline $\begin{array}{l}\text { Adverse events occurred after 120 } \\
\text { days of start of treatment }\end{array}$ & \multicolumn{2}{c}{ DLD } & & CHD \\
\hline Anemia, N (\%) & 0 & 0 & 0 & 0 \\
Leukopenia, N (\%) & 0 & 0 & 0 & 0 \\
Neutropenia, N (\%) & 0 & 0 & 0 & 0 \\
Thrombocytopenia, N (\%) & 0 & 0 & 0 & 0 \\
Cr-electrolyte nephrotoxicity, N (\%) & 3 & 10.7 & 2 & 12.5 \\
SCr-AKI, N (\%) & 0 & 0 & 0 & 0 \\
Electrolyte abnormalities, N (\%) & 0 & 0 & 0 & 0 \\
Chronic nephrotoxicity, N (\%) & 1 & 11.1 & 1 & 6.7
\end{tabular}

We found that electrolyte abnormalities and acute kidney toxicity related with low serum electrolyte was more likely to appear in the DLD group. It is difficult to explain the correlation of renal function and electrolyte abnormalities in the context of this study as eGFR and AKI-SCr analysis showed opposite results. However, we hypothesize this could be due to the concomitant radiotherapy the DLD group received during cisplatin administration. Incidence of acute esophageal toxicity tend to be higher in the DLD arm compared to sequential chemoradiation or radiotherapy only because of sensitizing 
TABLE 5 | Estimated glomerular filtration rate (eGFR) at baseline, at the end of chemotherapy, and 90 days after the last cisplatin administration in both treatment arms.

\begin{tabular}{lccc}
\hline Time of eGFR assessment & $\begin{array}{c}\text { Daily } \\
\text { low-dose }\end{array}$ & $\begin{array}{c}\text { Cyclic } \\
\text { high-dose }\end{array}$ & $\begin{array}{c}\text { B } \\
\mathbf{( 9 5 \% ~ C l ) ~}^{\mathbf{9}}\end{array}$ \\
\hline $\begin{array}{l}\text { At baseline ( } \mathrm{n}=115), \mathrm{ml} / \mathrm{min} / \\
1.73 \mathrm{~m}^{2} \text { (median; IQR) }\end{array}$ & $89.56 \pm 15.09$ & $92.30 \pm 14.94$ & $\begin{array}{c}8.49 \\
(1.86-15.13)\end{array}$ \\
$\begin{array}{l}\text { At the end of chemotherapy } \\
\text { ( } \mathrm{n}=96), \mathrm{ml} / \mathrm{min} / 1.73 \mathrm{~m}^{2}\end{array}$ & $86.17 \pm 18.86$ & $75.97 \pm 26.11$ & \\
(median; IQR) & & & \\
$\begin{array}{l}\text { 90 days after the last cisplatin } \\
\text { administration ( } \mathrm{n}=65), \mathrm{ml} / \mathrm{min} /\end{array}$ & $84.73 \pm 17.97$ & $81.91 \pm 21.45$ & \\
$1.73 \mathrm{~m}^{2}$ (median; IQR) & & & \\
\hline
\end{tabular}

${ }^{a}$ Result from generalized estimating equations (GEE) test, correcting for number of comorbidity and baseline albumin.

effect of cisplatin (Belderbos et al., 2005). A previous study at our institution reported that acute esophageal toxicity grade 1 occurred in $32 \%$ of the DLD patients, while $\geq$ grade 2 esophageal toxicity occurred in $57 \%$ of the patients treated with DLD (Uyterlinde et al., 2013). Esophagitis is characterized by mucosal atrophy, ulceration, inflammation (Choy et al., 1999; Nijkamp et al., 2013), and edema, leading to pain when swallowing. Thus, esophagitis may cause weight loss and malnutrition in DLD treated patients (Uyterlinde et al., 2013) which will affect the electrolyte intake from food and fluids.

Overall, we observed a milder toxicity profile of DLD cisplatin treatment as compared to the CHD cisplatin treatment except for electrolyte abnormalities. This milder toxicity profile indicates a slow decline over time of the blood cell counts and eGFR. We hypothesize that due to the constant daily administration, the patients could not recover from the decline before the next dose and therefore a linear decline in blood cell counts and eGFR over time is observed. On the other hand, the more severe toxicity profile in the CHD group indicates a rapid decline of blood counts and eGFR in the $\mathrm{CHD}$ group. However, due to the cyclic regimen the patient will be able to recover before the next cisplatin dose is received. Thereby, during the CHD regimen the blood counts and eGFR will follow a cyclic pattern of decline and increase over time, relative to the cisplatin dose. Thus, the results indicate that the incidence and severity of toxicity is directly related to the pharmacokinetics of cisplatin (Farris et al., 1988).

Furthermore, we know from other studies that the response on DLD treatment in terms of survival is equal to CHD treatment, thus less cumulative cisplatin dose still leads to the same therapeutic efficacy (Milano et al., 1990; Takata et al., 2002; Belderbos et al., 2007). Moreover, concurrent radiotherapy in the DLD regimen has an comparable safety profile to other radiotherapies (Kappers et al., 2011; Chen et al., 2013). The DLD regimen is equally effective as the standard CHD regimen while having a more favorable toxicity profile except for electrolyte abnormalities and acute nephrotoxicity marked by low serum electrolyte. Thus, while our results have to be validated in a prospective study, they deliver novel insights in cisplatin regimens that could help with future optimization of treatment regimen prescriptions.

A strength of this study is that we were able to perform a retrospective head-to-head comparison of two treatment regimens commonly applied in the centers included, of which the population represented current clinical practice in the Netherlands.

Some limitations of our study need to be addressed. Selection bias might have occurred in this study: patients with multiple comorbidities and lower cancer stage are less likely to receive CHD cisplatin treatment and will receive DLD treatment or radiotherapy. Therefore, the incidence of toxicity caused by the $\mathrm{CHD}$ regimen could be underestimated. Risk of selection bias also occurs as we included patients from different hospitals. However, there were no significant differences in clinical characteristics between DLD-treated patients between both institutions except in performance status. Because of limited power, some clinically significant differences may not be identified as statistically significant in this study. In addition, the study was limited by missing data. Especially the data on electrolyte concentrations was very limited, as the measurement was not incorporated in the standard clinical procedure. This might have led to an underestimation of the incidence and grading of acute nephrotoxicity in this study. However, it is likely that the missing values were not random: for patients performing well, electrolytes would not be measured; for patients who are performing worse, suspicion may have led to measurement of electrolytes. Therefore, we assume that the underestimation of acute nephrotoxicity is minimal. In addition, we specified the outcome to myelotoxicity and nephrotoxicity since other cisplatin toxicities such as nausea, vomiting, ototoxicity, and neurotoxicity were not regularly assessed. Finally, different chemotherapy doublets were included within the CHD group. From subgroup analysis we found that patients receiving the $\mathrm{CHD}$-gemcitabine combination have a higher risk of $\geq$ grade 2 leukopenia, neutropenia, and chronic nephrotoxicity compared to CHD-pemetrexed combination, confirming the effect of different antineoplastic combination on the toxicity (Table S2). However, since the scope of the study was to compare DLD cisplatin treatment to CHD cisplatin treatment, the differences in doublet therapy do represent current clinical practice.

In conclusion, this study demonstrates a higher risk on overall ( $\geq$ grade 1 ) toxicities in the DLD regimen, and a lower risk on moderate-to-severe ( $\geq$ grade 2 ) toxicities in the DLD regimen, as compared to the CHD regimen. However, the risk of electrolyte abnormalities during DLD regimen should be closely monitored in daily basis during therapy so that adequate supportive care intervention can be given appropriately. Based on our findings, choice of the cisplatin dose should be based on the patients' age, comorbidities as well as electrolyte status (Koning et al., 2010). Overall, the DLD regimen leads to equal therapeutic efficacy with a lower risk profile for moderate-to-severe toxicities, indicating that the DLD regimen could improve patients' quality of life. 


\section{DATA AVAILABILITY STATEMENT}

The datasets generated for this study are available on request to the corresponding author.

\section{ETHICS STATEMENT}

The studies involving human participants were reviewed and approved by Medisch Ethische Toetsingscommissie, Academisch Medisch Centrum (AMC) Universiteit van Amsterdam. The patients/participants provided their written informed consent to participate in this study.

\section{AUTHOR CONTRIBUTIONS}

Conceptualization: ZZ, JV, and A-HM-Z. Data curation: RK, JV, WU, ZZ, and PB. Formal analysis: ZZ, RK, and CL. Funding acquisition: ZZ, A-HM-Z. Investigation: ZZ, RK, JV, WU, CL, PB, RM, SV, and A-HM-Z. Methodology: ZZ, RK, JV, CL, PB, RM, SV, and A-HM-Z. Project administration: RK, RM, and A-HM-Z.

\section{REFERENCES}

Atmaca, A., Al-Batran, S. E., Werner, D., Pauligk, C., Guner, T., Koepke, A., et al. (2013). A randomised multicentre phase II study with cisplatin/docetaxel vs oxaliplatin/docetaxel as first-line therapy in patients with advanced or metastatic non-small cell lung cancer. Br. J. Cancer 108 (2), 265-270. doi: $10.1038 /$ bjc. 2012.555

Belderbos, J., Heemsbergen, W., Hoogeman, M., Pengel, K., Rossi, M., and Lebesque, J. (2005). Acute esophageal toxicity in non-small cell lung cancer patients after high dose conformal radiotherapy. Radiother. Oncol. : J. Eur. Soc. Ther. Radiol. Oncol. 75 (2), 157-164. doi: 10.1016/j.radonc.2005.03.021

Belderbos, J., Uitterhoeve, L., van Zandwijk, N., Belderbos, H., Rodrigus, P., van de Vaart, P., et al. (2007). Randomised trial of sequential versus concurrent chemo-radiotherapy in patients with inoperable non-small cell lung cancer (EORTC 08972-22973). Eur. J. Cancer (Oxford Engl. : 1990) 43 (1), 114-121. doi: 10.1016/j.ejca.2006.09.005

Besse, B., Adjei, A., Baas, P., Meldgaard, P., Nicolson, M., Paz-Ares, L., et al. (2014). 2nd ESMO Consensus Conference on Lung Cancer: non-small-cell lung cancer first-line/second and further lines of treatment in advanced disease. Ann. Oncol. 25 (8), 1475-1484. doi: 10.1093/annonc/mdu123

Biedermann, B., Landmann, C., Kann, R., Passweg, J., Soler, M., Lohri, A., et al. (2000). Combined chemoradiotherapy with daily low-dose cisplatin in locally advanced inoperable non-small cell lung cancer. Radiother. Oncol. : J. Eur. Soc. Ther. Radiol. Oncol. 56 (2), 169-173. doi: 10.1016/S0167-8140 (00)00203-6

Castelan-Martinez, O. D., Rodriguez-Islas, F., Vargas-Neri, J. L., Palomo-Colli, M. A., Lopez-Aguilar, E., Clark, P., et al. (2016). Risk Factors for Febrile Neutropenia in Children With Solid Tumors Treated With Cisplatin-based Chemotherapy. J. Pediatr. Hematol. Oncol. 38 (3), 191-196. doi: 10.1097/MPH.0000000000000515

Chen, C., Uyterlinde, W., Sonke, J. J., de Bois, J., van den Heuvel, M., and Belderbos, J. (2013). Severe late esophagus toxicity in NSCLC patients treated with IMRT and concurrent chemotherapy. Radiother. Oncol. 108 (2), 337-341. doi: 10.1016/j.radonc.2013.08.017

Choy, H., LaPorte, K., Knill-Selby, E., Mohr, P., and Shyr, Y. (1999). Esophagitis in combined modality therapy for locally advanced non-small cell lung cancer. Semin. Radiat. Oncol. 9 (2 Suppl 1), 90-96.
Resources: PB, RM, SV and A-HM-Z. Supervision: PB, SV, RM, and A-HM-Z. Visualization: ZZ and RK. Writing-original draft: ZZ and RK. Writing - review and editing: ZZ, RK, JV, WU, CL, PB, $\mathrm{RM}, \mathrm{SV}$, and A-HM-Z. All authors contributed to the article and approved the submitted version.

\section{FUNDING}

This work was supported by Indonesia Endowment Fund for Education (LPDP) Ministry of Finance, the Republic of Indonesia [as a part of ZZ's Ph.D. project, grant no. 20161022049506, 2016]. The funder had no role in the design of the study; in the collection, analyses or interpretation of data; in the writing of the manuscript or in the decision to publish the results.

\section{SUPPLEMENTARY MATERIAL}

The Supplementary Material for this article can be found online at: https://www.frontiersin.org/articles/10.3389/fphar. 2020.00975/full\#supplementary-material

Dilruba, S., and Kalayda, G. V. (2016). Platinum-based drugs: past, present and future Cancer Chemother. Pharmacol. 77 (6), 1103-1124. doi: 10.1007/s00280-016-2976-Z

Farris, F. F., Dedrick, R. L., and King, F. G. (1988). Cisplatin pharmacokinetics: applications of a physiological model. Toxicol. Lett. 43 (1-3), 117-137. doi: 10.1016/0378-4274(88)90024-0

Fennell, D. A., Summers, Y., Cadranel, J., Benepal, T., Christoph, D. C., Lal, R., et al. (2016). Cisplatin in the modern era: The backbone of first-line chemotherapy for non-small cell lung cancer. Cancer Treat Rev. 44, 42-50. doi: 10.1016/j.ctrv.2016.01.003

Hardy, D., Cormier, J. N., Xing, Y., Liu, C. C., Xia, R., and Du, X. L. (2010). Chemotherapy-associated toxicity in a large cohort of elderly patients with non-small cell lung cancer. J. Thorac. Oncol. 5 (1), 90-98. doi: 10.1097/ JTO.0b013e3181c0a128

Hartmann, J. T., and Lipp, H. P. (2003). Toxicity of platinum compounds. Expert Opin. Pharmacother. 4 (6), 889-901. doi: 10.1517/14656566.4.6.889

Kappers, I., Klomp, H. M., Koolen, M. G., Uitterhoeve, L. J., Kloek, J. J., Belderbos, J. S., et al. (2011). Concurrent high-dose radiotherapy with low-dose chemotherapy in patients with non-small cell lung cancer of the superior sulcus. Radiother. Oncol. : J. Eur. Soc. Ther. Radiol. Oncol. 101 (2), 278-283. doi: 10.1016/j.radonc.2011.05.030

Kidera, Y., Kawakami, H., Sakiyama, T., Okamoto, K., Tanaka, K., Takeda, M., et al. (2014). Risk factors for cisplatin-induced nephrotoxicity and potential of magnesium supplementation for renal protection. PloS One 9 (7), e101902. doi: 10.1371/journal.pone.0101902

Koning, C. C., Belderbos, J. S., and Uitterhoeve, A. L. (2010). From CisplatinContaining Sequential Radiochemotherapy towards Concurrent Treatment for Patients with Inoperable Locoregional Non-Small Cell Lung Cancer: Still Unanswered Questions. Chemother. Res. Pract. 2010, 506047. doi: 10.1155/ 2010/506047

Milano, G., Troger, V., Courdi, A., Fontana, X., Chauvel, P., and Lagrange, J. L. (1990). Pharmacokinetics of cisplatin given at a daily low dose as a radiosensitiser. Cancer Chemother. Pharmacol. 27 (1), 55-59. doi: 10.1007/BF00689277

Moon, H. H., Seo, K. W., Yoon, K. Y., Shin, Y. M., Choi, K. H., and Lee, S. H. (2011). Prediction of nephrotoxicity induced by cisplatin combination chemotherapy in gastric cancer patients. World J. Gastroenterol. 17 (30), 3510-3517. doi: 10.3748/wjg.v17.i30.3510 
Moreau, M., Klastersky, J., Schwarzbold, A., Muanza, F., Georgala, A., Aoun, M., et al. (2009). A general chemotherapy myelotoxicity score to predict febrile neutropenia in hematological malignancies. Ann. Oncol. 20 (3), 513-519. doi: 10.1093/annonc/mdn655

NCI (2010). Common Terminology Criteria for Adverse Events (CTCAE) v.4.03 (USA: National Cancer Institute), Available from: https://evs.nci.nih.gov/ftp1/ CTCAE/About.html.

Nijkamp, J., Rossi, M., Lebesque, J., Belderbos, J., van den Heuvel, M., Kwint, M., et al. (2013). Relating acute esophagitis to radiotherapy dose using FDG-PET in concurrent chemo-radiotherapy for locally advanced non-small cell lung cancer. Radiother. Oncol. : J. Eur. Soc. Ther. Radiol. Oncol. 106 (1), 118123. doi: 10.1016/j.radonc.2012.09.024

Nishikawa, M., Miyake, H., and Fujisawa, M. (2017). Identification of risk factors predicting febrile neutropenia in patients with metastatic germ cell tumors receiving cisplatin-based combination chemotherapy. Int. J. Urol. 24 (6), 449453. doi: $10.1111 /$ iju.13352

Pabla, N., and Dong, Z. (2008). Cisplatin nephrotoxicity: mechanisms and renoprotective strategies. Kidney Int. 73 (9), 994-1007. doi: 10.1038/sj.ki.5002786

Rose, M. C., Kostyanovskaya, E., and Huang, R. S. (2014). Pharmacogenomics of cisplatin sensitivity in non-small cell lung cancer. Genom. Proteomics Bioinf. 12 (5), 198-209. doi: 10.1016/j.gpb.2014.10.003

Schuster-Uitterhoeve, A. L., van de Vaart, P. J., Schaake-Koning, C. C., Benraadt, J., Koolen, M. G., Gonzalez Gonzalez, D., et al. (1996). Feasibility of escalating daily doses of cisplatin in combination with accelerated radiotherapy in nonsmall cell lung cancer. Eur. J. Cancer (Oxford Engl. : 1990) 32a (8), 1314-1319. doi: 10.1016/0959-8049(96)00077-9

Sharp, C. N., Doll, M. A., Dupre, T. V., Shah, P. P., Subathra, M., Siow, D., et al. (2016). Repeated administration of low-dose cisplatin in mice induces fibrosis. Am. J. Physiol. Renal Physiol. 310 (6), F560-F568. doi: 10.1152/ajprenal.00512.2015

Takata, I., Ueoka, H., Kiura, K., Tabata, M., Takigawa, N., Katayama, H., et al. (2002). Daily low-dose cisplatin and concurrent thoracic irradiation for poorrisk patients with unresectable non-small-cell lung cancer. Acta Med. Okayama 56 (5), 261-266. doi: 10.18926/amo/31705

Textor, J., van der Zander, B., Gilthorpe, M. S., Liskiewicz, M., and Ellison, G. T. (2016). Robust causal inference using directed acyclic graphs: the R package 'dagitty'. Int. J. Epidemiol. 45 (6), 1887-1894. doi: 10.1093/ije/dyw341

Uitterhoeve, A. L., Koolen, M. G., van Os, R. M., Koedooder, K., van de Kar, M., Pieters, B. R., et al. (2007). Accelerated high-dose radiotherapy alone or combined with either concomitant or sequential chemotherapy; treatments of choice in patients with Non-Small Cell Lung Cancer. Radiat. Oncol. (London England) 2, 27. doi: 10.1186/1748-717x-2-27

Uyterlinde, W., Chen, C., Kwint, M., de Bois, J., Vincent, A., Sonke, J. J., et al. (2013). Prognostic parameters for acute esophagus toxicity in intensity modulated radiotherapy and concurrent chemotherapy for locally advanced non-small cell lung cancer. Radiother. Oncol. : J. Eur. Soc. Ther. Radiol. Oncol. 107 (3), 392-397. doi: 10.1016/j.radonc.2013.04.012

Uyterlinde, W., Chen, C., Nijkamp, J., Obbink, M. G., Sonke, J. J., Belderbos, J., et al. (2014). Treatment adherence in concurrent chemoradiation in patients with locally advanced non-small cell lung carcinoma: results of daily intravenous prehydration. Radiother. Oncol. 110 (3), 488-492. doi: 10.1016/ j.radonc.2013.12.008

van Diessen, J. N., Chen, C., van den Heuvel, M. M., Belderbos, J. S., and Sonke, J. J. (2016). Differential analysis of local and regional failure in locally advanced nonsmall cell lung cancer patients treated with concurrent chemoradiotherapy. Radiother. Oncol. : J. Eur. Soc. Ther. Radiol. Oncol. 118 (3), 447-452. doi: 10.1016/ j.radonc.2016.02.008

Vansteenkiste, J., De Ruysscher, D., Eberhardt, W. E., Lim, E., Senan, S., Felip, E., et al. (2013). Early and locally advanced non-small-cell lung cancer (NSCLC): ESMO Clinical Practice Guidelines for diagnosis, treatment and follow-up. Ann. Oncol. 24 (Suppl 6), vi89-vi98. doi: 10.1093/annonc/mdt241

Yamamoto, Y., Watanabe, K., Matsushita, H., Tsukiyama, I., Matsuura, K., and Wakatsuki, A. (2017). Multivariate analysis of risk factors for cisplatin-induced nephrotoxicity in gynecological cancer. J. Obstet. Gynaecol. Res. 43 (12), 18801886. doi: $10.1111 /$ jog. 13457

Yu, J., Xiao, J., Yang, Y., and Cao, B. (2015). Oxaliplatin-Based Doublets Versus Cisplatin or Carboplatin-Based Doublets in the First-Line Treatment of Advanced Nonsmall Cell Lung Cancer. Medicine 94 (27), e1072. doi: $10.1097 / \mathrm{md} .0000000000001072$

Zazuli, Z., Vijverberg, S., Slob, E., Liu, G., Carleton, B., Veltman, J., et al. (2018). Genetic Variations and Cisplatin Nephrotoxicity: A Systematic Review. Front. Pharmacol. 9, 1111. doi: 10.3389/fphar.2018.01111

Zou, G. (2004). A modified poisson regression approach to prospective studies with binary data. Am. J. Epidemiol. 159 (7), 702-706. doi: 10.1093/ aje/kwh090

Conflict of Interest: The authors declare that the research was conducted in the absence of any commercial or financial relationships that could be construed as a potential conflict of interest.

Copyright (c) 2020 Zazuli, Kos, Veltman, Uyterlinde, Longo, Baas, Masereeuw, Vijverberg and Maitland-van der Zee. This is an open-access article distributed under the terms of the Creative Commons Attribution License (CC BY). The use, distribution or reproduction in other forums is permitted, provided the original author(s) and the copyright owner(s) are credited and that the original publication in this journal is cited, in accordance with accepted academic practice. No use, distribution or reproduction is permitted which does not comply with these terms. 